\title{
Neurosurgery in cerebral palsy
}

\author{
L. V. LAITINEN
}

From the Department of Neurosurgery, University Central Hospital, Helsinki, Finland

SUMMARY Stereotaxic subthalamotomy of 55 patients with cerebral palsy gave a good result in $65 \%$ of the selected cases. The result was uncertain in 15 and poor in $20 \%$. An independent sociomedical follow-up study confirmed the clinical finding. The more rapid the involuntary movements, the better was the effect of subthalamotomy. Intention tremor was the most suitable symptom for stereotaxic treatment. Rigidospasticity was alleviated in the distal muscles only. Speech and gait were often improved. Good results were obtained in patients with normal intelligence, while feebleminded patients did not benefit from the operation. Subthalamotomy was followed by transitory side-effects in $20 \%$, of which increased involuntary movements on the ipsilateral side and mental restlessness were the most frequent. The operation had no mortality. Spinal longitudinal myelotomy effectively relieved the spasticity of the lower limbs in the three patients operated upon.

Neurosurgical treatment of cerebral palsy was introduced 80 years ago, when the British neurosurgeon Victor Horsley (1890) showed that athetosis was improved by ablation of the cerebral motor cortex. In 1912, Winslow and Spear published an account of the beneficial results resulting from cutting the posterior spinal roots in athetosis and chorea. Later, Putnam (1933) interrupted spinal extrapyramidal tracts and reported diminution of involuntary movements.

When, in the 1940s, more general interest in surgery of the basal ganglia was aroused by the pioneer work of Russell Meyers (1942), it was already known that athetosis could be diminished to some degree by many neurosurgical interventions. The operations could be performed at several levels ranging from the cerebral cortex to the spinal roots. These operations either damaged the efferent motor pathways, causing paralysis, or interrupted some afferent feed-back connections necessary for adequate control of the fine movements.

Application of the stereotaxic principle to neurosurgery (Spiegel, Wycis, Marks, and Lee, 1947) raised hopes that a new means had been found to overcome the muscular hypertonia and athetosis of cerebral palsy. The new stereotaxic neurosurgery concentrated on Parkinsonism, the tremor and rigidity of which could be effectively abolished by lesions in the pallidum, pallido-thalamic pathways, ventrolateral thalamus, and subthalamus. It appears likely that in these operations afferent pathways conducting impulses to the premotor and motor cortex were severed and that the beneficial results were due to elimination of disturbances mediated by the feed-back control systems before they reached the pyramidal cells of the motor cortex. Therefore these operations did not produce paresis; on the contrary, they relieved the motor functions from the distressing tremor and rigidity.

Naturally, the stereotaxic technique was soon applied to cerebral palsy as well. The results were by no means so good as in Parkinsonism, on account of the difference between the underlying pathological processes. Quite encouraging results were reported, however-for example, by Narabayashi (1962). Some neurosurgeons, on the other hand, were rather disappointed with their results (Yasargil, 1962; Maspes and Pagni, 1965). In 1965 Maspes and Pagni published their results of pedunculotomy in cerebral palsy, an operation developed by Walker (1949), which aims at interruption of the motor pyramidal tract in the cerebral peduncle and which more or less completely paralyses one half of the body. Maspes and Pagni were satisfied with their results and concluded that pedunculotomy was a better operation in cerebral palsy than thalamotomy.

The vast difference in the results of thalamic surgery for cerebral palsy may partly have depended on subjectivity in the evaluation of the results, but also on the choice of the target area, on the accuracy of the stereotaxic technique, on the standard of the electrophysiological control of individual variations of the deep structures, on the size of the lesion, and, 
finally, on the selection of the patients for surgical treatment. It seems quite evident that some patients are better suited for these operations than others, a matter on which this study throws some light.

Spinal operations for the treatment of spasticity have increased in number during recent years. The idea of these interventions is usually to interrupt the reflex arc. Longitudinal myelotomy (Bischof, 1951) has been used by myself in various types of spastic paraplegia, including cerebral palsy. Chemical destruction of the spinal nerve roots with alcohol, phenol, or hypertonic saline is practised in some hospitals.

The stereotaxic technique has recently been applied to the cerebellar nuclei (Heimburger and Whitlock, 1965; Heimburger, 1967; Zervas, Horner, and Pickren, 1967; Krayenbühl and Siegfried, 1969; Nashold and Slaughter, 1969).

In this paper I shall report on my personal series of surgical treatment in cerebral palsy and discuss the results.

\section{PATIENTS AND METHODS}

The present series consists of 60 selected patients with cerebral palsy, on whom 70 neurosurgical interventions had been carried out. These patients are divided in this study into four groups (Table 1). Group I consists of three patients, 10 to 23 years old, who all had such severe extension spasticity of the lower limbs that they were unable to sit at all. On these three patients I carried out a longitudinal thoracolumbar myelotomy. The reflex arc was bilaterally dissected between the dorsal and ventral roots through a 5 to $6 \mathrm{~cm}$ long medullary incision, the caudal end of which lay about $3 \mathrm{~cm}$ cranial to the lowest tip of the conus terminalis.

Group II consists of 39 patients, 3 to 23 years old, who had a 'typical' severe athetosis and rigidospasticity of the trunk and extremities. On the basis of the nature of the involuntary movements these patients were divided into subgroups of rapid and slow athetosis. In some of these patients the involuntary movements could have been classified as choreic or ballistic, and these patients were always placed in the rapid-movement group. On these 39 patients, 47 subthalamotomies were carried out. Eight patients were operated on bilaterally.

Group III consists of 16 patients, 17 to 44 years old. These were patients who had already passed childhood, and who often had unilateral or predominantly unilateral symptoms, consisting of athetosis and intention tremor. The intelligence of these patients was good, while groups I and II included patients with a clear or suspected defect of intelligence. These 16 patients underwent subthalamotomy, two of them in both thalami.

The target in the subthalamus was the same as I use in Parkinsonism. It lay 3 to $4 \mathrm{~mm}$ behind the midcommissural point, on the intercommissural line, and 11 to $12 \mathrm{~mm}$ lateral to the midline of the third ventricle. Air ventriculography in connection with the operation showed normal ventricles in 50 patients, and slightly dilated ventricles in five. Three patients showed a cavum septi pellucidi.

The electrode was driven to the target by means of a small electric motor and the brain tissue impedance was continuously measured during the insertion. The impedance of the internal capsule was 25 to $50 \%$ higher than that of the thalamus, which made it possible to judge with a high degree of accuracy when the electrode reached the thalamus and subthalamus. As soon as the electrode had been inserted into the target, an electric stimulation $(60 \mathrm{~Hz}, 1 \mathrm{msec}, 2$ to $6 \mathrm{~V})$ was performed. The responses consisted of athetoid movements or of alteration of tremor in the contralateral limbs and of a deviation o $\vec{D}$ the homolateral eye inwards and downwards. An ip silateral mydriasis was seen in some patients. The presumable size of the electrocoagulation lesion was $6 \mathrm{mn \delta}$ in diameter. According to the stereotaxic atlas of Schalt enbrand and Bailey (1959), the lesion presumably lay ine the zona incerta and at the ventral boundary of the v.o.p. nucleus of the thalamus. Eighteen of the 55 patients of groups II and III were operated on under local anaesthesia.

Group IV consists of two patients who had a stereotaxic operation to the dentate nucleus. The operation was unilateral in one and bilateral, performed at one session, in the other case. These two patients suffered from severe rigidospasticity with few and small involuntary movements.

TABLE 1

NATURE OF INVOLUNTARY MOVEMENTS AND MUSCULAR HYPERTONIA IN 60 PATIENTS WITH CEREBRAL PALSY

\begin{tabular}{|c|c|c|c|c|c|c|c|c|c|c|c|}
\hline \multirow{3}{*}{ Group } & \multirow{3}{*}{$\begin{array}{l}\text { Patients } \\
\text { (no.) }\end{array}$} & \multirow{3}{*}{ Mean age } & \multicolumn{2}{|c|}{ Athetosis } & \multirow{3}{*}{$\begin{array}{c}\text { Intention } \\
\text { Tremor }\end{array}$} & \multirow{3}{*}{ Ataxia } & \multirow{2}{*}{\multicolumn{2}{|c|}{$\begin{array}{c}\text { Muscular } \\
\text { hypertonia }\end{array}$}} & \multicolumn{3}{|c|}{ Intelligence } \\
\hline & & & \multirow{2}{*}{ Slow } & \multirow{2}{*}{ Rapid } & & & & & Normo & $t k n o$ & Low \\
\hline & & & & & & & Mild & Severe & & & \\
\hline I & 3 & $\begin{array}{c}16 \\
(10-23)\end{array}$ & 3 & - & - & - & - & 3 & 2 & - & 1 \\
\hline II & 39 & $\begin{array}{c}11 \\
(3-23)\end{array}$ & 21 & 17 & 1 & - & 12 & 27 & 25 & 9 & 5 \\
\hline III & 16 & $\begin{array}{c}25 \\
(17-44)\end{array}$ & 2 & 9 & 15 & 2 & 6 & 2 & 16 & - & - \\
\hline IV & 2 & $\begin{array}{c}16 \\
(13-19)\end{array}$ & 2 & - & - & - & - & 2 & 2 & - & - \\
\hline & 60 & & 28 & 26 & 16 & 2 & 18 & 34 & 45 & 9 & 6 \\
\hline
\end{tabular}




\section{EVALUATION OF RESULTS}

In order to make the clinical evaluation of the operative results as objective as possible, the point score system illustrated in Fig. 1 was used. Some signs and functions were evaluated with points ranging from 0 to 3 . Nought corresponded to a normal condition and 3 to the maximal degree of severity. The right and left sides were evaluated separately and the right-left relationship was expressed as a percentage. If the relationship definitely changed in favour of the side operated upon, the result was considered good. The relatives of the patients as well as the rehabilitation per- sonnel were interviewed. Electromyographic (EMG) examinations were also used. If all four sources indicated a good result, the overall result was taken as good. If the sources gave contradictory results, the overall result was classed as uncertain and if no source indicated improvement or one source showed impairment, the result was considered to be poor.

The assessment of the intelligence level and of the speech and language functions of the cerebral palsied children was often very difficult or even impossible. The following test battery was used: Wechsler intelligence scale for children, Eisenson aphasia tests, KTK performance test (in Finnish), Goldstein-Scheerer test of abstract and concrete

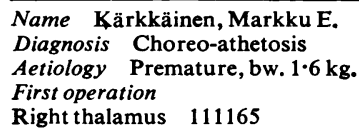

Name Kärkkäinen, Markku E.

Diagnosis Choreo-athetosis

Aetiology Premature, bw. 1.6kg.

First operation

Right thalamus 111165

Born 100154 Age 11 yrs

Second operation 
thinking, and Raven matrix test of perception. The results of the preoperative intelligence testing of this series are summarized in Table 1.

The follow-up time ranged from one to seven years with an average of three years.

\section{RESULTS}

The results are shown in Table 2 . It can be seen that all patients who underwent a longitudinal myelotomy showed improvement, particularly in so far as that they were able to sit for the first time, which made further rehabilitation easier. The legs became flaccid and areflexic. One patient had a suspect sensory defect in one leg and two had urinary incontinence which persisted for three months.

In group II a good result was obtained in $54 \%$. The effect was uncertain in 23 and poor in $23 \%$. Diminution of involuntary movements in the contralateral limbs was the feature most often leading to a good result. The muscular hypertonia diminished in the distal parts of the extremities. The hand and fingers often became completely free of spasms, while the rigidospasticity of the proximal muscles and of the trunk remained unchanged.

Dysarthria increased in one patient of group II and in one patient of group III, but the speech cleared up within three months. No language deterioration was observed after surgery, but it must be emphasized that its assessment was often unreliable. An independent socio-medical study of the present series indicated that the speech of three patients had suffered from surgery, although this was only twice clinically observed.

Some patients learned to walk after operation. Since the muscular hypertonia in the feet diminished, the patients were able to attain a better position of the foot, which was important for gait training. It is evident that some of the good results were due to intensified rehabilitation after surgery.
Eight patients $(20 \%)$ in group II showed various complications. Increased involuntary movements ipsilateral to the thalamotomy and mental restlessness were the most frequent side-effects. Mental deterioration increased after surgery in one patient. The side-effects were never very severe, but in some patients they accounted for the scoring of the poor or uncertain overall result of treatment.

In group III, in which the patients had a combination of athetosis and intention tremor, the operative results were definitely better than in the previous group. The only poor result was possibly due to a technical imperfection. It was easy to verify the results in this group, since the patients were able to talk and perform the tests better than the children of group II. The side-effects in this group were much the same as in the second group.

Group IV comprises two patients, who had an operation to the dentate nucleus. The result in the first case was nil, possibly because the lesion was very small. In the other case, the objective result was uncertain, although the patient himself was convinced of a marked improvement.

There was no operative mortality in this series.o One patient died three years after surgery frons respiratory infection.

\section{DISCUSSION}

The predominantly good results in the syndrome of athetosis-intention tremor again demonstrate the old observation that intention tremor responds verf favourably to thalamotomy (Laitinen, 1965). This syndrome is not uncommon in Finland, as is shown by the percentage of patients displaying it in the present series. Intention tremor is usually completely abolished by thalamotomy, while the athetosis remains largely unchanged. The athetosis-intention tremor seldom prevents a child from all use of the affected hand, and therefore I prefer to postpone the

\begin{tabular}{|c|c|c|c|c|c|c|c|c|c|c|c|c|c|c|}
\hline \multirow[b]{2}{*}{ Group } & \multirow[b]{2}{*}{$\begin{array}{c}\text { Patients } \\
\text { (no.) }\end{array}$} & \multirow[b]{2}{*}{$\begin{array}{c}\text { Opera- } \\
\text { tions } \\
(\text { no. })\end{array}$} & \multicolumn{3}{|c|}{ Results } & \multicolumn{9}{|c|}{ Complications } \\
\hline & & & Good & Uncertain & Poor & $\begin{array}{l}\text { Impaired } \\
\text { speech }\end{array}$ & $\begin{array}{c}\text { Increased } \\
\text { involuntary } \\
\text { movements }\end{array}$ & $\begin{array}{l}\text { Epileptic } \\
\text { fits }\end{array}$ & $\begin{array}{c}\text { Urinary } \\
\text { inconti- } \\
\text { nence }\end{array}$ & $\begin{array}{c}\text { Mental } \\
\text { changes }\end{array}$ & Hemiparesis & $\begin{array}{c}\text { Sensory } \\
\text { defect }\end{array}$ & $\begin{array}{c}\text { Disturbed } \\
\text { balance }\end{array}$ & Death \\
\hline I & 3 & 3 & 3 & - & - & - & - & - & 2 & - & - & 1 & - & - \\
\hline II & 39 & 47 & 21 & G & 9 & 1 & 2 & 1 & - & 2 & 1 & - & 1 & - \\
\hline III & 16 & 18 & 15 & - & 1 & 1 & 2 & 1 & - & $\overline{1}$ & - & - & 1 & - \\
\hline IV & 2 & 2 & - & 1 & 1 & - & - & - & - & - & - & - & - & - \\
\hline Total & 60 & 70 & 39 & 10 & 11 & 2 & 4 & 2 & 2 & 3 & 1 & 1 & 2 & - \\
\hline
\end{tabular}

TABLE 2

RESULTS AND COMPLICATIONS OF NEUROSURGICAL TREATMENT OF CEREBRAL PALSY 
operation until the mid-teens, when the brain has reached its final size and the operation can be carried out under local anaesthesia.

The effect of subthalamotomy on the athetosis was beneficial in $50 \%$ of the patients selected for this intervention. If the athetosis patients of groups II and III are divided into two subgroups on the basis of the rapidity of the involuntary movements, as in Table 3, good results seem to be more common in the rapid-movement group. It is a generally accepted opinion that patients with cerebral palsy who have very slow athetosis and in whom the spasticity dominates are not good subjects for thalamic surgery. The results of cerebellar surgery may bring hope for these patients, although the first reports are confusing. Heimburger (1967) obtains a muscular hypotonia and diminution of athetosis on the contralateral side of the body, while others report that the effect is ipsilateral to the dentate lesion (Zervas et al., 1967; Krayenbühl and Siegfried, 1969; Nashold and Slaughter, 1969).

\section{TABLE 3}

COMPARISON OF RAPIDITY OF ATHETOTIC MOVEMENTS AND RESULT OF THALAMATOMY IN 43 PATIENTS OPERATED UPON FOR CEREBRAL PALSY

\begin{tabular}{lcccc}
\hline \multirow{2}{*}{ Athetosis } & \multicolumn{3}{c}{ Clinical result } & Total \\
\cline { 2 - 5 } & + & $?$ & - & \\
\hline Slow & 10 & 5 & 7 & 22 \\
Rapid & 15 & 5 & 1 & 21 \\
\hline Total & 25 & 10 & 8 & 43 \\
\hline
\end{tabular}

The intelligence of the patients plays an important part (Table 4). No patient of this series with low intelligence benefited from the operation. It seems likely that after the operation an intelligent patient is more alert and active than a mentally feeble patient. This increases the chances of rehabilitation.

In order to gain an idea of the social benefit to be derived from the stereotaxic treatment of cerebral palsy, the Institute of Social and Preventive Medicine of the University of Helsinki made a study of 39 cerebral palsied patients operated upon at least one year previously. These patients were included in my present study. Their investigation showed that $72 \%$ of the patients had become better, $24 \%$ were unchanged, and $4 \%$ had become worse than they were before surgery. Eighty per cent of the patients were living at home. The most common feature of the improvement was the improved motor ability. Fifty per cent had less involuntary movements
TABLE 4

COMPARISON OF PATIENTS' INTELLIGENCE AND CLINICAL RESULTS IN 57 PATIENTS OPERATED UPON FOR CEREBRAL PALSY

\begin{tabular}{lrccc}
\hline Intelligence & \multicolumn{3}{c}{ Clinical result } & Total \\
\cline { 2 - 5 } & + & $?$ & - & \\
\hline Normal & 30 & 6 & 7 & 43 \\
Not known & 6 & 3 & - & 9 \\
Low & - & 1 & 4 & 5 \\
\hline Total & 36 & 10 & 11 & 57 \\
\hline
\end{tabular}

than before surgery. The treatment of the patients had become easier. Speech difficulties had improved in $29 \%$, and were impaired in $10 \%$ (three patients) as a result of surgery (Holmberg and Trappe, 1969).

\section{REFERENCES}

Bischof, W. (1951). Die longitudinale myelotomie. $\mathrm{Zbl}$. Neurochir., 11, 79-88.

Heimburger, R. F., and Whitlock, C. C. (1965). Stereotaxic destruction of the human dentate nucleus. Confin. neurol. (Basel), 26, 346-358.

Heimburger, R. F. (1967). Dentatectomy in the treatment of dyskinetic conditions. Confin. neurol. (Basel), 29, 101-106.

Holmberg, P. C., and Trappe, B. (1969). A socio-medical follow-up study of CP-patients treated stereotaxically. (Unpublished.)

Horsley, V. (1890). Remarks on the surgery of the central nervous system. Brit. med. J., 2, 1286-1292.

Krayenbühl, H., and Siegfried, J. (1969). La chirurgie stéréotaxique du noyau dentelé dans le traitement des hyperkinésies et des états spastiques. Neuro-Chirurgie, 15, 51-58.

Laitinen, L. (1965). Stereotaxic treatment of hereditary tremor. Acta neurol. scand., 41, 74-79.

Maspes, P. E., and Pagni, C. A. (1965). Surgical treatment of dystonia and choreo-athetosis in infantile cerebral palsy by pedunculotomy. Pathophysiological observations and therapeutic results. J. Neurosurg., 21, 10761086.

Meyers, R. (1942). The present status of surgical procedures directed against the extrapyramidal diseases. N.Y.St. J. Med., 42, 535-543.

Narabayashi, H. (1962). Stereotaxic surgery for athetosis or the spastic state of cerebral palsy. Confin. neurol. (Basel), 22, 364-367.

Nashold, Jr., B. S., and Slaughter, D. G. (1969). Effects of stimulating or destroying the deep cerebellar regions in man. J. Neurosurg., 31, 172-186.

Putnam, T. J. (1933). Treatment of athetosis and dystonia by section of extrapyramidal motor tracts. Arch. Neurol. Psychiat. (Chic.), 29, 504-521.

Schaltenbrand, G., and Bailey, P. (1959). Introduction to Stereotaxis with an Atlas of the Human Brain. Thieme: Stuttgart.

Spiegel, E. A., Wycis, H. T., Marks, M., and Lee, A. J. (1947). Stereotaxic apparatus for operations on the human brain. Science, 106, 349-350.

Walker, A. E. (1949). Cerebral pedunculotomy for the 
relief of involuntary movements. 1. Hemiballismus. Acta psychiat. scand., 24, 723-729.

Winslow, R. and Spear, I. J. (1912). Section of posterior spinal nerve roots for relief of gastric crises and athetoid and choreiform movements. Report of two cases. $J$. Amer. med. Ass., 58, 238-240.
Yasargil, M. G. (1962). Die Ergebnisse der stereotaktischen Operationen bei Hyperkinesien. Schweiz. med. Wschr., 92, 1550-1555.

Zervas, N. T., Horner, F. A., and Pickren, K. S. (1967). The treatment of dyskinesia by stereotaxic dentatectomy. Confin. neurol. (Basel), 29, 93-100. 